\title{
A kinetic study of the complete oxidation of ethene, propane and their mixtures on a $\mathrm{Pd} / \mathrm{Al}_{2} \mathrm{O}_{3}$ catalyst
}

\author{
L. van de Beld, M. C. van der Ven, K. R. Westerterp* \\ Chemical Reaction Engineering Laboratories, Department of Chemical Engineering, University of Twente, P.O. Box 217, \\ NL-7500 AE Enschede, Netherlands \\ Received 18 November 1994; accepted 9 January 1995
}

\begin{abstract}
The complete oxidation of ethene and propane as individual hydrocarbons and of their mixtures on a $\mathrm{Pd} / \mathrm{Al}_{2} \mathrm{O}_{3}$ catalyst has been studied using an internal recycle reactor. The pressure was varied from $1.6-5$ bar and the temperature from $180-220^{\circ} \mathrm{C}$ for ethene oxidation and from $280-330^{\circ} \mathrm{C}$ for propane oxidation. The maximum hydrocarbon concentration was ca. $3000 \mathrm{ppm}$ or $0.3 \mathrm{vol} . \%$.

The effect of the reaction products and the co-educt on the kinetics was investigated and it is shown that whereas water significantly retards the oxidation, the influence of $\mathrm{CO}_{2}$ is negligible. Propane oxidation is inhibited by ethene. Such inhibition can only partly be explained by the additional water formed due to the combustion of ethene. The conversions in these experiments studied ranged between $70 \%$ and $90 \%$ for ethene and between $15 \%$ and $30 \%$ for propane, respectively.

Four different rate expressions have been tested bearing in mind that the influence of water must be taken into account in any adequate description of the experimental data. The best-fitting rate expression described the experimental data to within an average error of $17 \%$ for ethene and $13 \%$ for propane, respectively.

A comparison of the results with data from dynamic experiments showed a reasonable agreement.
\end{abstract}

Keywords: Kinetic study; Ethene complete oxidation; Propane complete oxidation; Ethene/propane mixtures complete oxidation; $\mathrm{Pd} / \mathrm{Al}_{2} \mathrm{O}_{3}$ catalyst

\section{Introduction}

Catalytic combustion can be applied for the destruction of volatile organic compounds (VOCs) in polluted air (see, for example, Prasad et al. [1] and Zwinkels et al. [2]). Recently several research groups, have studied the behaviour of catalytic after-burners (see, for example, Tichenor and Palazzolo [3], Mazzarino and Barresi [4] and Hermia and Vigncron [5]).

We have studied the catalytic oxidation of VOCs in a number of catalytic packed bcd rcactors in our laboratory (see Van de Beld et al. $[6,7]$ ) with both a.o. ethene and propane being used as sample substances. For the description and prediction of the behaviour of such

\footnotetext{
* Corresponding author.
}

leactors, a knowledge of the reaction system is necessary. In this paper, we report on kinetic studies of the complete oxidation of ethene and propane on a $\mathrm{Pd} / \gamma$ $\mathrm{Al}_{2} \mathrm{O}_{3}$ catalyst involving the following reactions:

$$
\begin{aligned}
\mathrm{C}_{2} \mathrm{H}_{4}+3 \mathrm{O}_{2} & \rightarrow 2 \mathrm{CO}_{2}+2 \mathrm{H}_{2} \mathrm{O} \\
\Delta H_{298 \mathrm{~K}} & =-1322 \mathrm{~kJ} \mathrm{~mol}^{-1} \\
\mathrm{C}_{3} \mathrm{H}_{8}+5 \mathrm{O}_{2} & \rightarrow 3 \mathrm{CO}_{2}+4 \mathrm{H}_{2} \mathrm{O} \\
\Delta H_{298 \mathrm{~K}} & =-2043 \mathrm{~kJ} \mathrm{~mol}^{-1}
\end{aligned}
$$

The influence of the reaction products on the oxidation process is discussed and since the oxidation of hydrocarbon mixtures might deviate from the behaviour of the individual hydrocarbons in the absence of other compounds, (see, for example, Spivey [8] and Barresi and Baldi [9]) the influence of ethene on the oxidation of propane has been investigated and vice versa. 
The kinetic experiments were performed in an internal recycle reactor. Such a reactor allows temperature and concentrations gradients to be largely avoided and is therefore very suitable for kinetic experiments.

\section{Kinetic models}

There is no general consensus on the mechanism of catalytic oxidation reactions in the literature (see the review of Spivey [8]). Depending on the specific catalyst and hydrocarbons studied, different mechanisms have been proposed. Under the conditions used in this work, i.e. a large excess of oxygen with propane and ethene as low concentration contaminants and a palladium catalyst, it is usually assumed that chemisorption of oxygen followed by reaction with gaseous hydrocarbon is the mechanism involved. The reaction products, $\mathrm{CO}_{2}$ and $\mathrm{H}_{2} \mathrm{O}$, may retard the oxidation reaction. Almost all the authors quoted in the literature have neglected the influence of $\mathrm{CO}_{2}$. Assuming that water adsorbs onto the adsorbed oxygen, the following reaction rate expression can be obtained (see Golodets [10] for its detailed deviation):

$R_{\mathrm{HC}}=\frac{k_{2} P_{\mathrm{O}_{2}} k_{1} P_{\mathrm{HC}}}{k_{2} P_{\mathrm{O}_{2}}\left(1+K_{\mathrm{H}_{2} \mathrm{O}} P_{\mathrm{H}_{2} \mathrm{O}}\right)+v k_{1} P_{\mathrm{HC}}}$

while for the reaction rate constant, $k_{1}$, an Arrhenius temperature dependence is assumed:

$k_{1}=k_{1, \infty} \mathrm{e}^{-E_{\text {act }} / R T}$

Table 1 lists four different rate expressions which have been uscd to describe the cxpcriments. Models I, II and III can be derived from Eq. (1) with Model III being equivalent to Eq. (1) provided $k_{1}^{\prime}=v k_{1} / k_{2} P_{\mathrm{O}_{2}}$. If the surface reaction is much slower than oxygen adsorption, then $v k_{1} P_{\mathrm{HC}} \ll k_{2} P_{\mathrm{O}_{2}}$ and model II is obtained. A further simplification can be achieved by neglecting the influence of water on the process, which is possible if $K_{\mathrm{H}_{2} \mathrm{O}} P_{\mathrm{H}_{2} \mathrm{O}} \ll 1$ : this yields the rate expression given by model I. Model IV is a power law rate expression which cannot be deduced from Eq. (1). Such

Table 1

Kinetic rate expressions for the complete oxidation of ethene and propane

\begin{tabular}{|c|c|}
\hline Model & Reaction rate expression \\
\hline I & $R_{\mathrm{HC}}=k_{1, \infty} \mathrm{e}^{-E_{\mathrm{uut}} / R T} \cdot P_{\mathrm{HC}}$ \\
\hline II & $R_{\mathrm{HC}}=\frac{k_{1, \infty} \mathrm{e}^{-E_{\mathrm{Har} / R T}^{T}} \cdot P_{\mathrm{HC}}}{1+K_{\mathrm{H}_{2} \mathrm{O}} \cdot P_{\mathrm{H}_{2} \mathrm{O}}}$ \\
\hline III & $R_{\mathrm{HC}}=\frac{k_{1, \infty} e^{-E_{\mathrm{u}, \mathrm{H}} / R T} \cdot P_{\mathrm{HC}}}{1+K_{\mathrm{H}_{2} \mathrm{O}} \cdot P_{\mathrm{H}_{2} \mathrm{O}}+k_{1}^{\prime} \cdot P_{\mathrm{HC}}}$ \\
\hline IV & $R_{\mathrm{HC}}=k_{r, \infty} \mathrm{e}^{-E_{\mathrm{utt}} / R T} \cdot P_{\mathrm{HC}}^{n} \cdot P_{\mathrm{H}_{2} \mathrm{O}}^{m}$ \\
\hline
\end{tabular}

a model does not provide any insight into the mechanism of the reaction. However, for engineering purposes, it might be convenient and often yields good results provided it is not used for extrapolation outside the experimental range.

\section{Experimental details}

Figure 1 shows a schematic drawing of the experimental installation. Experiments were performed in a Berty-type internal recycle reactor with a volume of 0.51 . The reactor basket was filled with $10-30 \mathrm{~g}$ of the $\mathrm{Pd} / \mathrm{Al}_{2} \mathrm{O}_{3}$ catalyst. For details of the catalyst, see Table 2. A magnetically driven impeller provided internal recirculation of the gas in the reactor, the rotational speed of the impeller being controlled by an electronic frequency controller with a maximum speed of ca. $1500 \mathrm{rpm}$. The catalyst and gas temperatures were measured in the top part of the catalyst bed using two $\mathrm{K}$-type thermocouples. The temperature in the reactor was regulated by means of an eurotherm temperature controller. The reactor pressure was maintained at its set-point by means of a mechanical back-pressure controller. The maximum allowable pressure in the system was 5 bar, as measured at the top of the reactor with a TransInstruments electron pressure gauge.

Air containing small amounts of ethene and/or propane was fed into the reactor, the air flow and concentrations of the hydrocarbons being controlled by means of Brooks thermal mass flow controllers. Water could be added to the feed by leading part of the air stream through a water evaporation vessel, the water concentration being varied by changing the air flow through the vessel. Additional $\mathrm{CO}_{2}$ could also be introduced to the feed. In case of emergency or when the system needed to be purged, nitrogen was fed into the reactor instead of the usual feed.

The hydrocarbon concentrations in the inlet and outlet streams were measured using a Varian gas chromatograph equipped with a $2 \mathrm{~m} \times 1 / 8 \mathrm{in}$ column packed with $80-100$ mesh Deactigel. The column was operated at $60^{\circ} \mathrm{C}$. A flame ionisation detector was used for detecting the hydrocarbons. The $\mathrm{CO}_{2}$ concentration was monitored continuously using a Maihak $610 \mathrm{CO}_{2}$ infrared analyzer. Unfortunately, it was not possible to monitor the $\mathrm{CO}$ concentration. The water concentration in the inlet stream was determined using a Panametrics chilled-mirror dew point hygrometer.

Since the inlet and outlet concentrations of the hydrocarbons and $\mathrm{CO}_{2}$ were determined, overall mass balance of the reactor led to the following equation for the experimental reaction rate:

$R_{\text {exp }}=\frac{F_{\mathrm{f}, j}-F_{\text {out }, j}}{M_{\text {cat }}}$ 


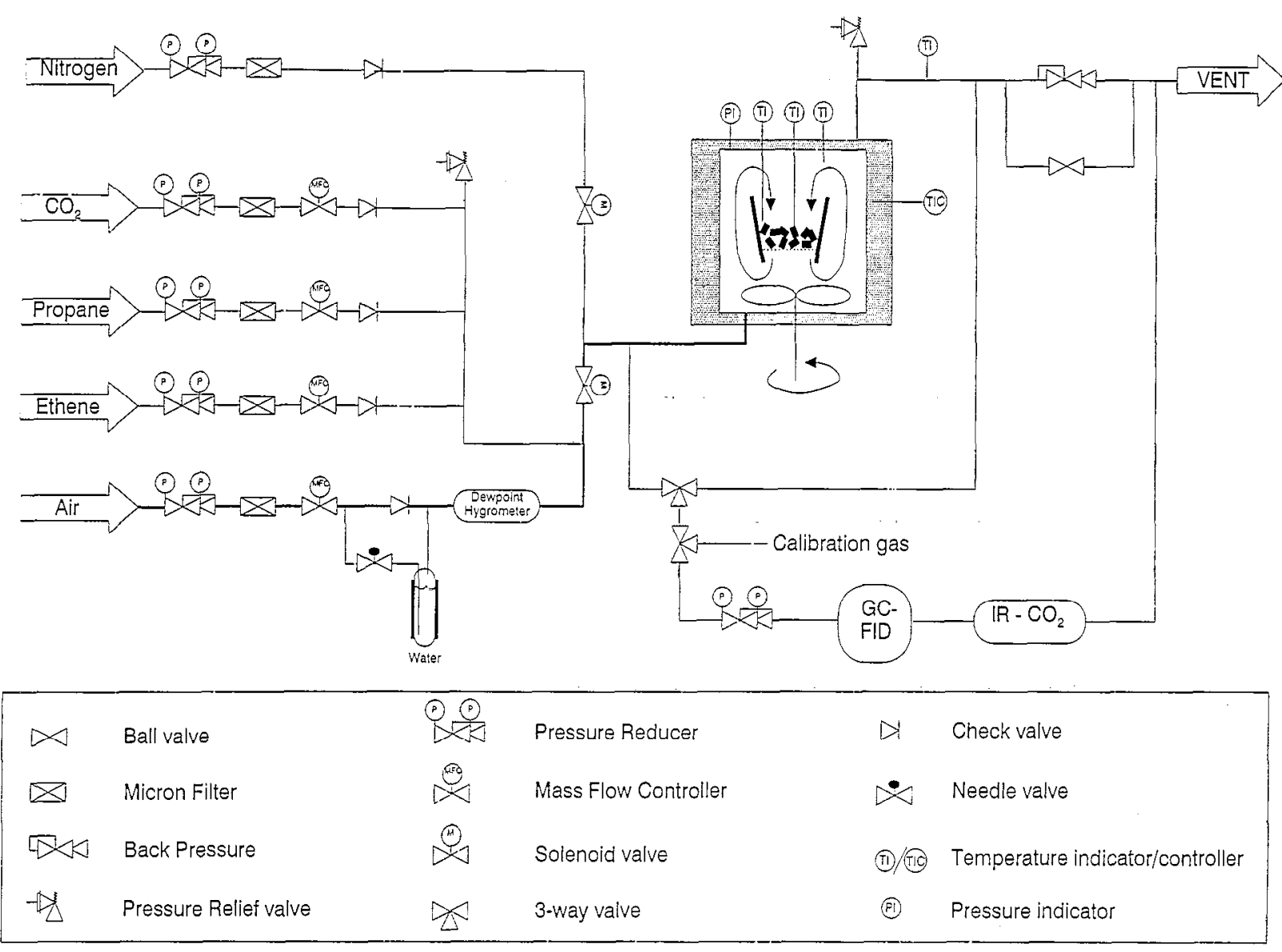

Fig. 1. Schematic drawing of experimental set-up employed.

Estimation of the parameters in the kinetic rate expressions listed in Table 1 was achieved using the SIMUSOLV program of Dow Chemical [11]. This program determines the optimum parameter values using the maximum likelihood principle.

\section{Results and discussion}

The performance of a Berty reactor is mainly controlled by the recycle ratio. This ratio must be sufficiently high to avoid concentration and temperature gradients in the reactor. Wedel and Villadsen [12] have discussed inaccuracies in the kinetic parameters due to

Table 2

Catalyst properties

$\mathrm{Pd} / \gamma-\mathrm{Al}_{2} \mathrm{O}_{3}$ cylinders

diameter, $4.5 \mathrm{~mm}$; height, $4.5 \mathrm{~mm}$

particle density, $1327 \mathrm{~kg} \mathrm{~m}^{-3}$

approximate bed density, $796 \mathrm{~kg} \mathrm{~m}^{-3}$

active metal surface area $350 \mathrm{~m}^{2} \mathrm{~kg}^{-1}$

BET surface area $192 \mathrm{~m}^{2} \mathrm{~g}^{-1}$

Pd content, 0.07 wt. $\%$

$\mathrm{Pd}$ on outer surface only; penetration depth, $<0.1 \mathrm{~mm}$ improper performance, particularly as a result of concentration gradients. Borman [13] has proposed a criterion to take account not only of concentration but also of temperature gradients. Since the experimental determination of the recycle ratio is difficult and inaccurate, some experimental tests have been undertaken to check on the appropriate nature of the reactor. These tests showed that (i) the reaction rates were not influenced by the rolation speed $N$ of the impeller provided $N$ was greater than $800 \mathrm{rpm}$; (ii) interchanging the inlet and outlet of the reactor did not affect the conversion rates; and (iii) the temperature difference between the catalyst and the gas was small, being typically less than $1-2 \mathrm{~K}$. Interchanging the inlet and outlet allowed the number of passes through the catalyst bed to be increased by one. From these three tests we conclude that the recycle ratio was sufficiently high to assume the reactor to be perfectly mixed for our kinetic experiments.

First-order kinetics are often assumed for the complete oxidation of hydrocarbons. In Fig. 2, the reaction rate of propane has been plotted as a function of the partial pressure of propane $P_{\text {propane }}$ for different temperatures. The increase in the reaction rate with increasing $P_{\text {propane }}$ is less than proportional. This indicates an inhibition by the reaction products or a reaction order less than unity with respect to propane. The lines 


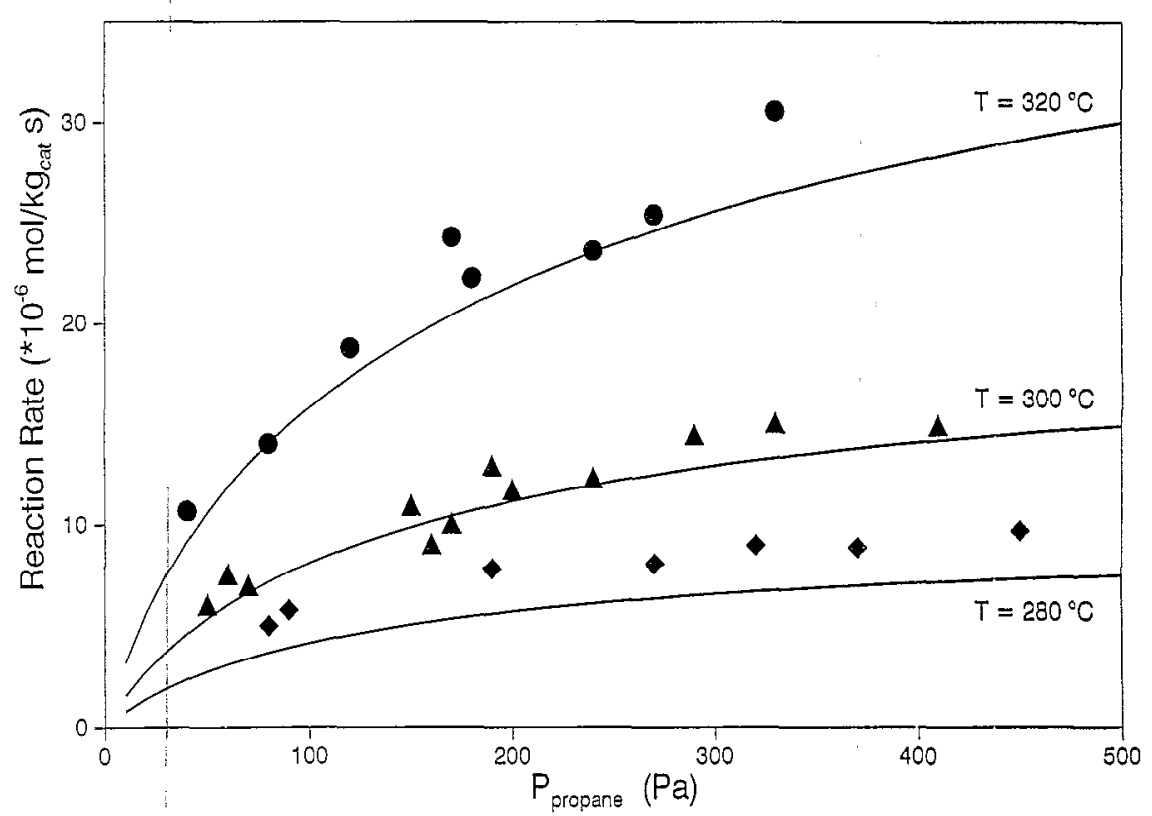

Fig. 2. Reaction rate of propane as a function of the propane partial pressure at different temperatures: $P=2.0$ bar, lines calculatcd using model III (see Tables 1 and 3 ).

in Fig. 2 were calculated using model III, the most extensive model employed. At low and high temperatures, the model appears to underrate the experimental data but, in general, the agreement is acceptable.

The reaction products, $\mathrm{CO}_{2}$ and $\mathrm{H}_{2} \mathrm{O}$, may influence the oxidation of ethene and propane. In most studies quoted in the literature, the influence of $\mathrm{CO}_{2}$ was found to be negligible (see, for example, Trimm and Lam [14], Cullis et al. [15] and Kemball and Patterson [16]). However, Ribeiro et al. [17] observed an abrupt decrease in the methane oxidation rate as soon as the $\mathrm{CO}_{2}$ concentration exceeded 0.5 vol. \%. Below this value no effect was found. In Fig. 3, the reaction rates of propane and ethene obtained in the present study have been plotted as a function of the $\mathrm{CO}_{2}$ concentration, with all other conditions kept constant. The results indicate that neither ethene nor propane oxidation was affected by the addition of $\mathrm{CO}_{2}$ to the feed gas.

In contrast to the effect of $\mathrm{CO}_{2}$, most authors have found severe inhibition of the reaction by water. Thus, Ribeiro et al. [17] found a reaction order of -1 for $\mathrm{H}_{2} \mathrm{O}$ in the oxidation of methane. Simon and Vort-

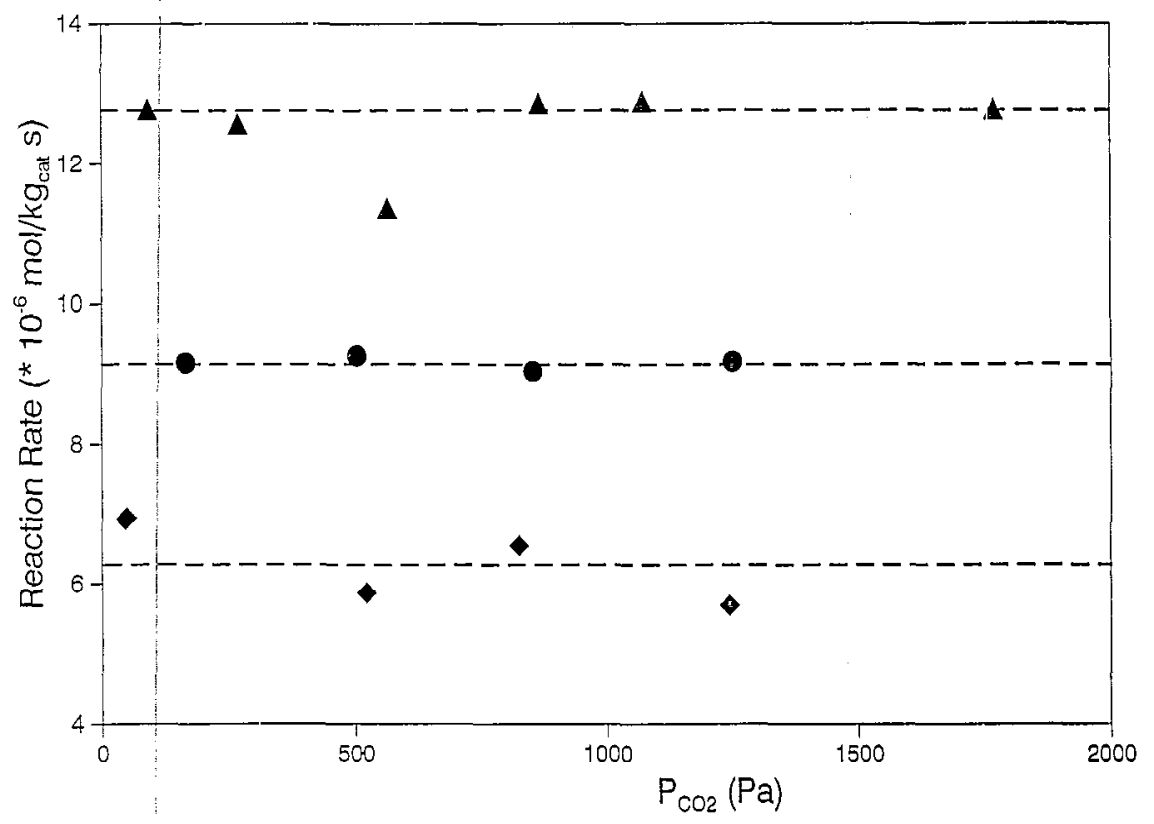

Fig. 3. Influence of $\mathrm{CO}_{2}$ on the reaction rates of propane and ethene: $\boldsymbol{\mu}, P_{\text {cthene }}=175 \mathrm{~Pa}, T=208^{\circ} \mathrm{C} ; \bullet, P_{\text {propane }}=162 \mathrm{~Pa}, T=300{ }^{\circ} \mathrm{C} ; \bullet$, $P_{\text {ethene }}=175 \mathrm{~Pa}, T=197^{\circ} \mathrm{C}$. 


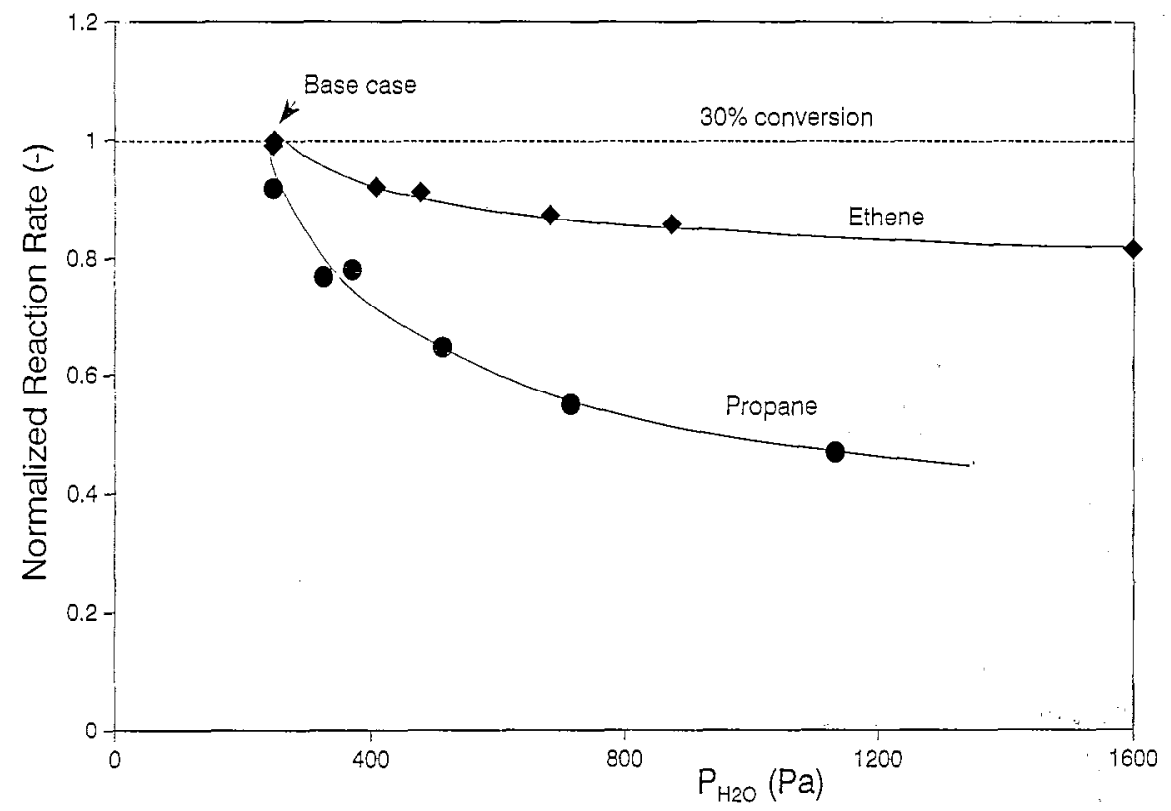

Fig. 4. Influence of water content on the normalized reaction rate of ethene and propane, respectively, defined as the actual reaction rate divided by the reaction rate in the absence of water: $\mathrm{P}=2 \mathrm{bar} ; \bullet, P_{\text {ethene }}=250 \mathrm{~Pa}, T=208^{\circ} \mathrm{C} ; \boldsymbol{\bullet}, P_{\text {propane }}=182 \mathrm{~Pa}, T=300^{\circ} \mathrm{C}$.

meyer [18] in a study of ethane oxidation on a Pd catalyst found a reaction order for water varying from 0 to -0.7 depending on the temperature employed. However, Kemball and Patterson [16] did not observe any inhibition by water of the oxidation of ethene on Pd. It should be noted that, in contrast to other studies, they used an unsupported catalyst. In Fig. 4, the normalized reaction rate, i.e. the actual reaction rate divided by the rate observed without addition of water or ethene to the feed, has been plotted as a function of the water pressure in the reactor. The results show that both ethene and propane oxidation are inhibited by water, but the effect on the propane reaction is much stronger with the conversion rate for propane being reduced by a factor of two for high water contents. Using the power law rate expression, the reaction order of water was found to be -0.12 and -0.46 for ethene and propane, respectively.

Mutual inhibition effects were observed during the simultaneous oxidation of ethene and propane. For this reason, we have studied the influence of ethene on propane combustion and vice versa. First we discuss

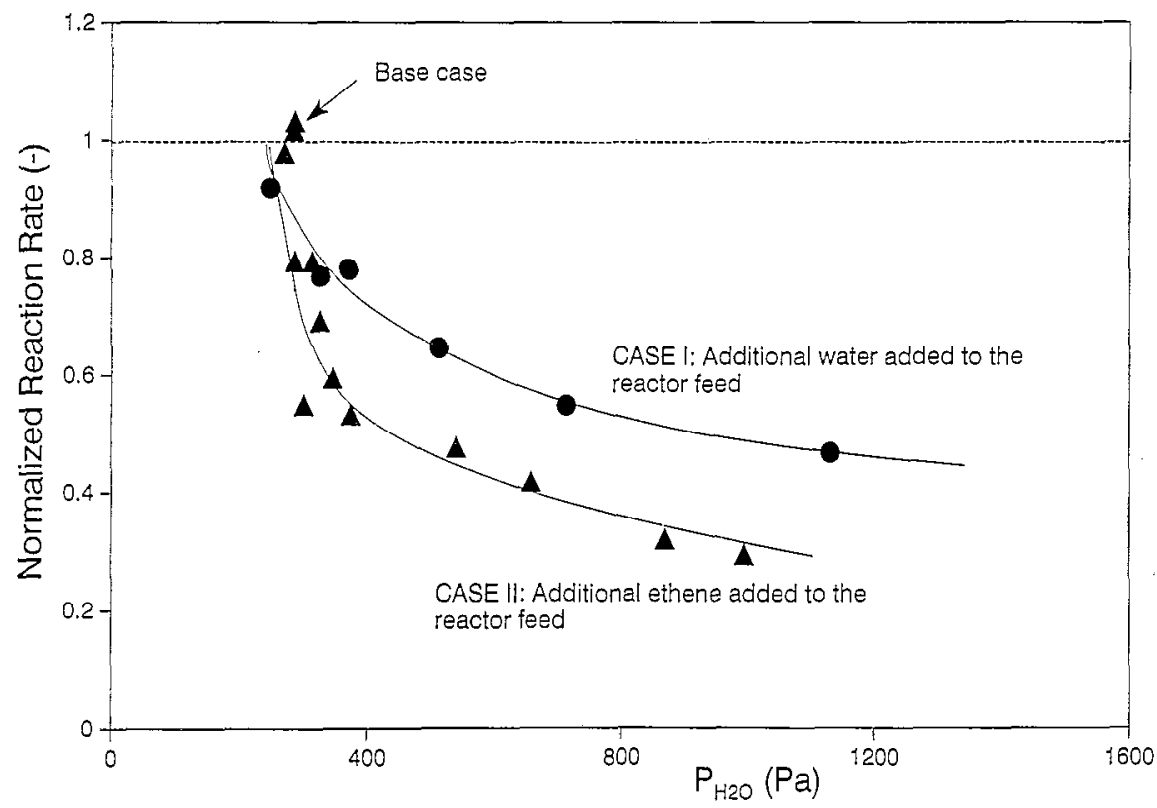

Fig. 5. Influence of water content on the normalized reaction rate for the simultaneous oxidation of ethene and propane, defined as the actual reaction rate divided by the reaction rate in the absence of water or ethene: $P=2$ bar; $\bullet, P_{\text {propane }}=182 \mathrm{~Pa}, T=300{ }^{\circ} \mathrm{C} ; \boldsymbol{\Lambda}, P_{\text {propane }}$ $(=185 \mathrm{~Pa})+P_{\text {ethene }}(=0.250 \mathrm{~Pa}), T=300^{\circ} \mathrm{C}$. 
the influence of ethene on propane oxidation. Under the kinetic conditions employed for the propane reaction, ethene has already reached a very high conversion and hence more $\mathrm{H}_{2} \mathrm{O}$ and $\mathrm{CO}_{2}$ will be generated. Thus, in comparison to experiments/without ethene addition, the $\mathrm{H}_{2} \mathrm{O}$ and $\mathrm{CO}_{2}$ concentrations in the reactor are higher. Since, as discussed above, water significantly retards propane oxidation, it is possible that the inhibition induced by ethene may also be caused by the increased water concentration. This is supported by the results depicted in Fig. 5, in which the normalized reaction rate of propane combustion is plotted versus the water concentration for two different cases: (i) where the water concentration in the reactor was increased by the addition of water to the reactor feed and (ii) where the water concentration in the reactor was increased by the addition of ethene to the feed and attributed to the consecutive oxidation of ethene to $\mathrm{H}_{2} \mathrm{O}$ and $\mathrm{CO}_{2}$ in the reactor.

For the base case, i.e. without addition of water or ethene to the feed, the water ontent in the reactor was about $250 \mathrm{~Pa}$ due to the conversion of propane. Figure 5 shows that in both instances the reaction rate for propane oxidation decreased with increasing water concentration. Conversions were between $70 \%$ and $90 \%$ for ethene and between $15 \%$ and $30 \%$ for propane, respectively. In addition the decrease in the oxidation rate for propane was larger for case II than for case I. In case II, only ethene was added and hence the decrease in activity was caused by the water produced and by another inhibiting agent. It is assumed that the presence of unconverted ethene or of an (unknown) adsorbed intermediate product also retards the oxidation of propane, since $\mathrm{CO}_{2}$ was shown to have no effect.

The addition of propane did not affect the reaction of ethene. In these experiments, the temperature employed was so low that the conversion of propane was negligible.

The models listed in Table 1 have been fitted to the experimental data. Best fit values for the kinetic parameters of these models are listed in Table 3. Fig- ures 6 and 7 show a comparison of the measured reaction rates with the model predictions for ethene and propane, respectively. In both cases model I, i.e. the simplest model, gives the poorest results. However, for the combustion of ethene, model II, III and IV perform equally well. For the oxidation of propane, the best results are obtained with model IV. Despite the slightly higher mean error involved, model III is preferred for the prediction of the reaction rate of propane because its derivation is based on a reaction mechanism.

We also used a different experimental installation to obtain numerical values for the kinetic parameters. For a detailed description, refer to van de Beld et al. [7]. The main differences were:

1. A dynamic method (DM) was used. The renctor was operated under transient conditions whereas the Berty reactor was operated in a stationary state. The dynamic method was much faster, but less accurate.

2. The reactor behaved like a plug-flow reactor whereas the Berty reactor should be perfectly mixed.

The kinetic data obtained from both installations could be compared by calculating the conversion versus temperature profiles for an isothermal plug-fiow reactor, for which the following mass balance applies:

$0=-\frac{\mathrm{d}\left(u_{\mathrm{g}} C_{j}\right)}{\mathrm{d} z}-R_{j}(1-\epsilon) \rho_{\mathrm{s}}$

The reaction rate $R_{j}$ may be calculated using the models and data given in Tables 1 and 3 , respectively. The rate expression for the dynamic method is similar to model I. The curves for total conversion versus temperature were calculated as follow's: at a given operating temperature, the total conversion over the reactor may be calculated by integrating Eq. (4) for an isothermal reactor with a certain bed length. This led to an outlet conversion for the chosen kinetic model and reactor temperature. The process was then repeated for the various models and temperatures.

Figure 8 shows plots of the calculated conversion for ethene and propane derived from the different kinetic

Table 3

Best fit values for parameters involved in the oxidation of ethene and propane as derived from the various models listed in Table 1

\begin{tabular}{|c|c|c|c|c|c|c|c|c|c|c|}
\hline \multirow[t]{2}{*}{ Parameter } & \multicolumn{2}{|l|}{ Ethene } & \multirow[b]{2}{*}{ II } & \multirow[b]{2}{*}{ III } & \multirow[b]{2}{*}{ IV } & \multicolumn{5}{|l|}{ Propane } \\
\hline & $\mathrm{DM}^{\mathrm{a}}$ & I & & & & $D M^{a}$ & I & II & III & IV \\
\hline$E_{\mathrm{act}}\left(\mathrm{kJ} \mathrm{mol}^{-1}\right)$ & 67.3 & 57.8 & 58.9 & 57.4 & 43.2 & 87.7 & 92.9 & 153.7 & 101.2 & 119.3 \\
\hline$k_{1, \approx}$ or $k_{\mathrm{r}, \approx}$ & $1.2 \times 10^{0}$ & $1.8 \times 10^{-1}$ & $3.2 \times 10^{-1}$ & $2.3 \times 10^{-1}$ & $4.3 \times 10^{2}$ & $7.2 \times 10^{0}$ & $1.4 \times 10^{1}$ & $9.9 \times 10^{8}$ & $3.2 \times 10^{2}$ & $4.8 \times 10^{5}$ \\
\hline$K_{\mathrm{H}_{2} \mathrm{O}}\left(\mathrm{Pa}^{-1}\right)$ & - & - & $9.4 \times 10^{-4}$ & $8.7 \times 10^{-4}$ & - & - & - & $5.3 \times 10^{-1}$ & $1.5 \times 10^{-3}$ & - \\
\hline$k_{\mathrm{i}}^{\prime}\left(\mathrm{Pa}^{-1}\right)$ & - & - & - & $2.3 \times 10^{-4}$ & - & - & - & - & $9.1 \times 10^{-3}$ & - \\
\hline$n$ & - & - & - & - & 0.71 & - & - & - & - & 0.61 \\
\hline$m$ & - & - & - & - & -0.12 & - & - & - & - & -0.46 \\
\hline Error $(\%)$ & - & 19.7 & 16.6 & 16.4 & 16.6 & - & 31.8 & 17.6 & 13.7 & 12.5 \\
\hline
\end{tabular}

aData obtained from experiments using a dynamic method. Reaction rate expression same as in model ] (see Ref. [7]). 

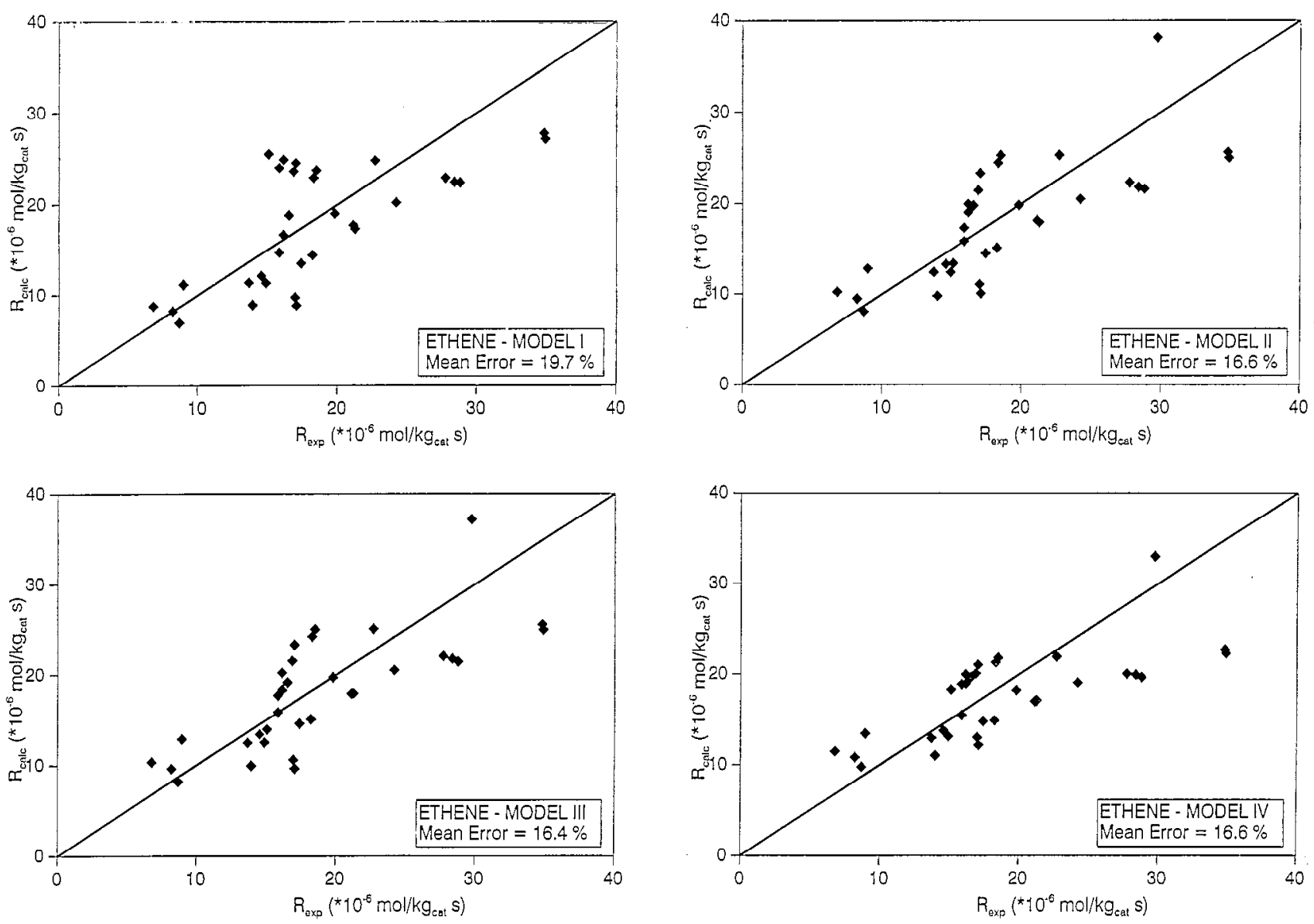

Fig. 6. Calculated reaction rates for ethene oxidation according to the different models versus the measured values. For models employed, see Table 1

models as a function of the bed temperature in the reactor. Under the usual operating conditions applied, the calculated conversions for kinetic models I-IV are comparable. Extrapolation to higher temperatures led to significant differences for both components.

The conversion profile has also been calculated by making use of the kinetic data obtained with the dynamic method DM. This profile is compared to the results obtained with model III in Fig. 9. Although the agreement is satisfactory for the oxidation of propane, significant differences are observed for the oxidation of ethene. Thus, when the kinetic data obtained with the dynamic method DM are employed, a higher conversion of ethene is found. Hence the activity of the catalyst used in the Berty reactor appears to be lower. This apparent difference in activity may be explained by the different conditions under which the catalyst is exposed in both installations, with a constant catalyst activity being difficult to achieve in the Berty reactor.

Over a substantial period of time, the rate of ethene oxidation decreased with time on-stream. However, the original activity could be regained by treatment of the catalyst at higher temperatures. This is illustrated in Fig. 10 where the catalyst was first exposed to ethene oxidation for $2 \mathrm{~h}$ at $320^{\circ} \mathrm{C}$. The experiment was then repeated, and it was observed that initially ethene conversion was even higher than previously. Similar observations have been made by Hawkins and Wanke [19] for ethene oxidation over a Pl catalyst. Such reversible catalyst deactivation did not occur with the dynamic method since in that case the catalyst was heated up to $600^{\circ} \mathrm{C}$ prior to carrying out the oxidation reaction. Hence, with the dynamic method, the catalyst always operated at high initial activity and for this reason, depending on the operating conditions, the kinetic data obtained with the dynamic method probably give a more correct prediction of the behaviour of a catalytic packed-bed reactor, despite the lower accuracy of this method.

\section{Conclusions}

Kinetic experiments for the total oxidation of ethene and propane, and of their mixtures on a $\mathrm{Pd} / \gamma-\mathrm{Al}_{2} \mathrm{O}_{3}$ catalyst have been carried out in a Berty reactor. The influence of the reaction products, $\mathrm{H}_{2} \mathrm{O}$ and $\mathrm{CO}_{2}$, was also investigated. The addition of $\mathrm{CO}_{2}$ to the feed did not alter the rates of oxidation. However, water strongly retarded the conversion rates for both ethene 

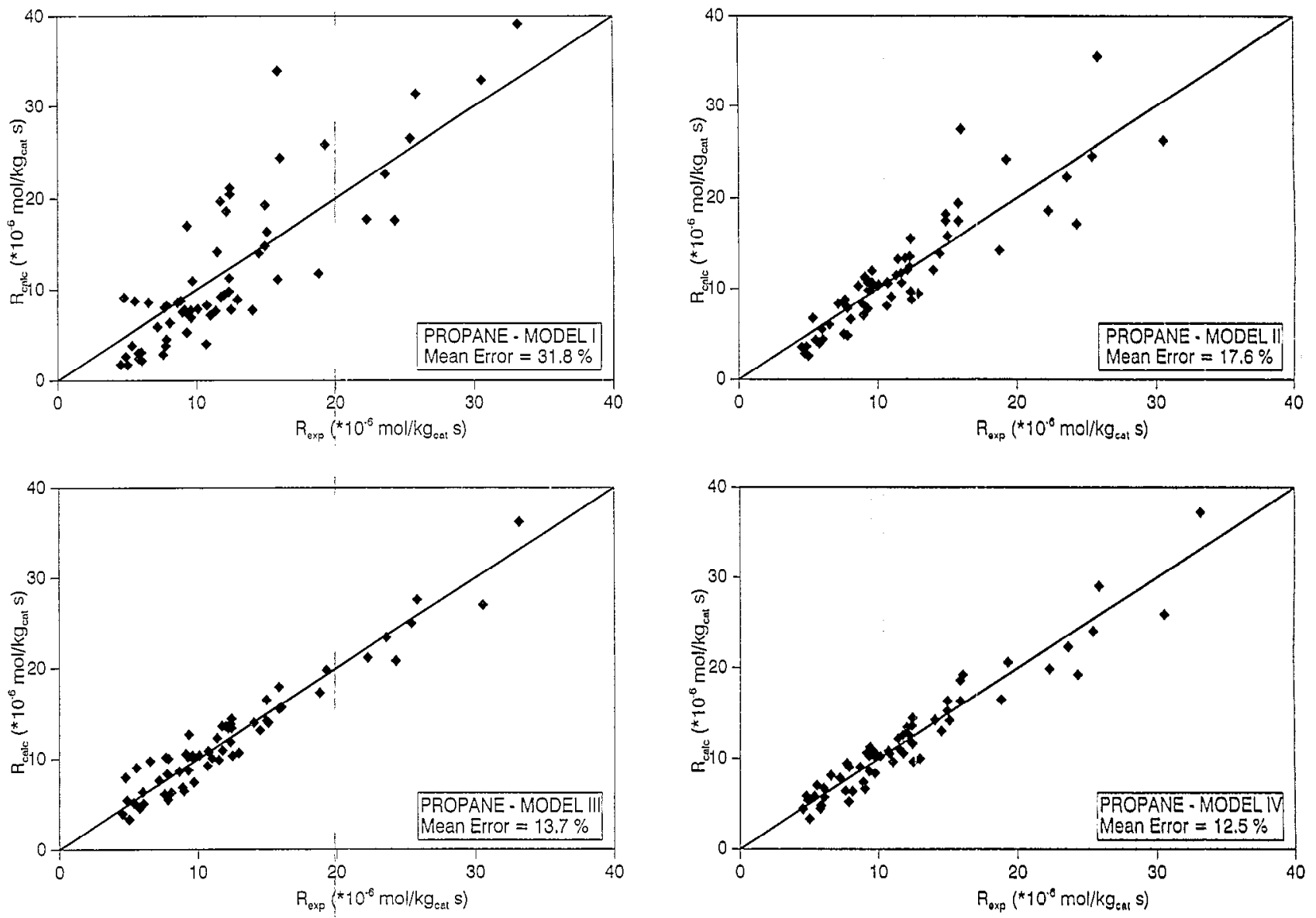

Fig. 7. Calculated reaction rates for propane oxidation according to the different models versus the measured values. For models employed, see Table 1.

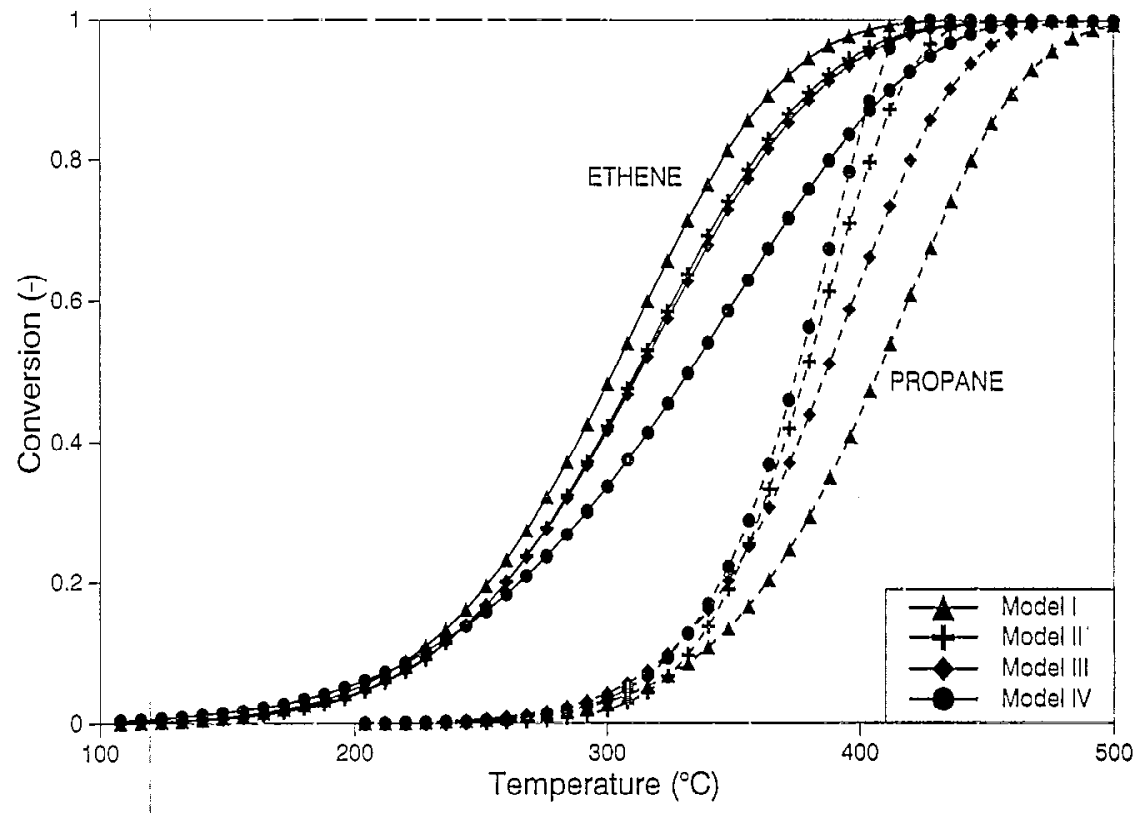

Fig. 8. Calculated conversions for the individual oxidations of ethene and propane as a function of the operating temperature for an isothermal packed-bed reactor using the different kinetic models listed in Table 1. The kinetic data used in the calculations are given in Table 3. The following values were employed: $u_{\mathrm{g}}=0.20 \mathrm{~m} \mathrm{~s}^{-1}, L=0.10 \mathrm{~m}, C_{\text {propane, in }}=1000 \mathrm{ppm}, C_{\text {ethene, in }}=1000 \mathrm{ppm}$.

and propane. Through the use of a power law rate expression, the reaction order of water was determined as -0.12 and -0.46 for ethene and propane, respec- tively. The rate of oxidation for propane decreased when ethene was present in the feed. Under the conditions employed for propane oxidation, ethene conver- 


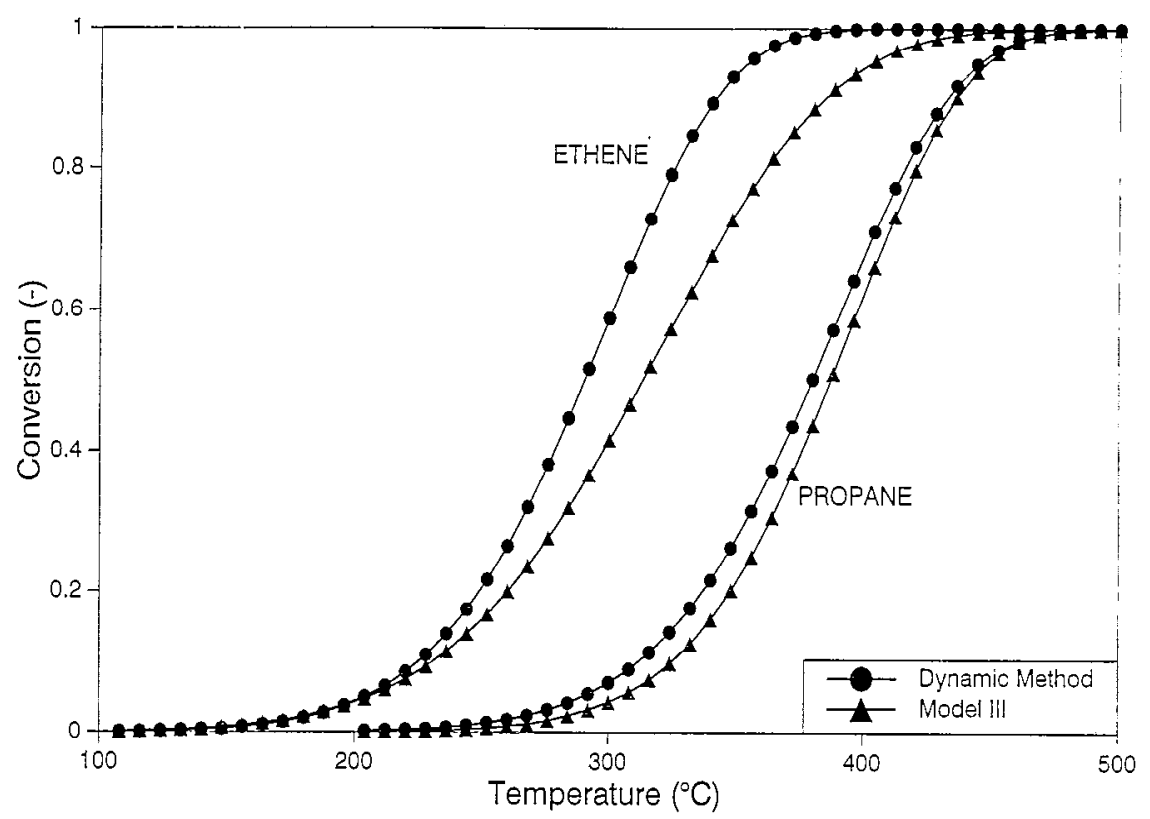

Fig. 9. Calculated conversions for the individual oxidations of ethene and propane as a function of the operating temperature for an isothermal packed-bed reactor. The kinetic data used in the calculations are given in Table 3 . The following values were employed: $u_{\mathrm{g}}=0.20 \mathrm{~ms}^{-1}$, $L=0.10 \mathrm{~m}, C_{\text {ethene, in }}=1000 \mathrm{ppm}, C_{\text {propune, in }}=1000 \mathrm{ppm}$.

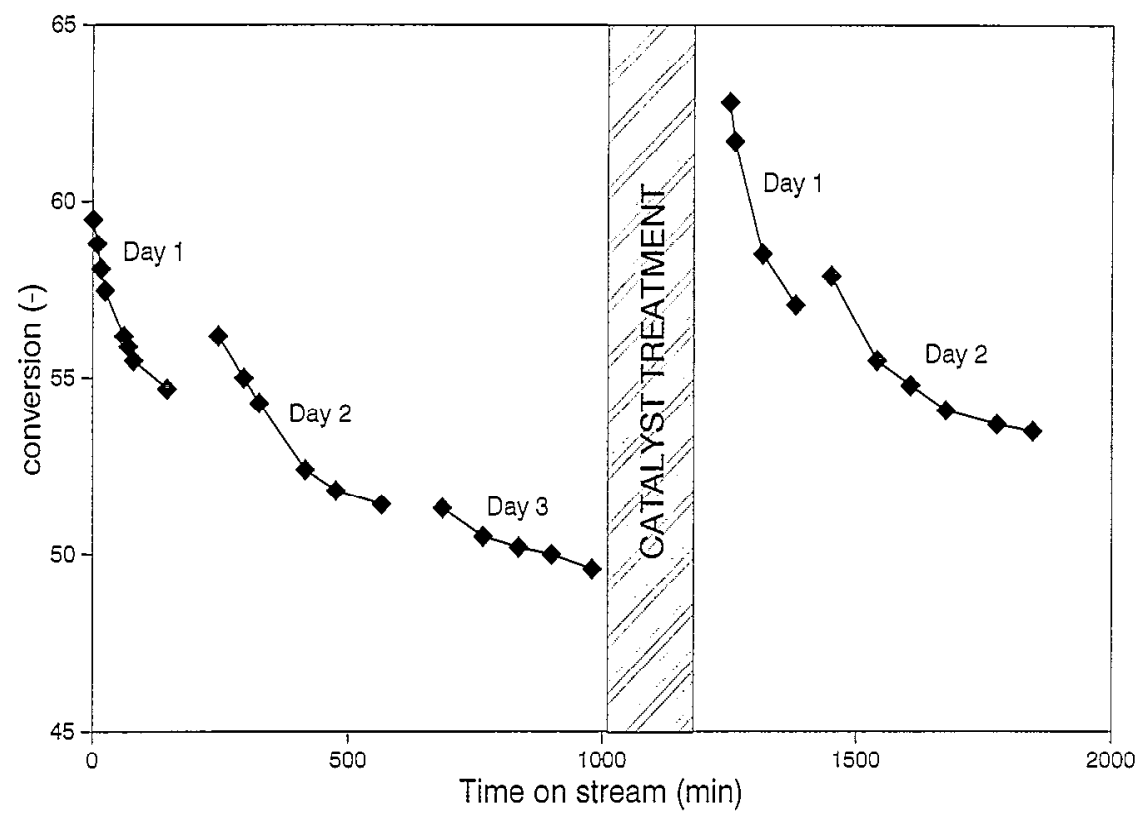

Fig. 10. Ethene conversion as a function of time on-stream: $P=2.00$ bar, $T=220^{\circ} \mathrm{C}, C_{\text {ethene in }}=2630$ ppm; catalyst treatment, $T=320^{\circ} \mathrm{C}$. All other conditions remained the same.

sion is already high and significant amounts of water were produced. However, the additional water formed by the conversion of ethene did not completely explain such inhibition by ethene. In the studies undertaken, the conversions were between $70 \%$ and $90 \%$ for ethene, and between $15 \%$ and $30 \%$ for propane. Ethene oxidation was not affected by the presence of propane.

Four different reaction rate expressions have been tested for fitting the experimental data. The best rate expressions fitted the experimental data with an average error of $17 \%$ for ethene oxidation and $13 \%$ for propane oxidation, respectively.

On the basis of conversion profiles calculated for a packed-bed reactor, the kinetic data were compared with results obtained using a dynamic measuring technique. Good agreement was observed for propane oxidation. However, with ethene combustion the conversion rate calculated using the kinetic data from the Berty reactor was lower which may be explained by differences in the operating conditions for both reactors. 


\section{Acknowledgements}

The investigations reported were supported by the Netherlands' Foundation for Chemical Research (SON) with financial aid from the Netherlands' Technology Foundation and DSM. The authors wish to thank R. $T$. Tromp for performing part of the experimental work and G. H. Banis, F. ter Borg, K. van Bree, O. D. Veehof and A. H. Pleiter for technical assistance.

\section{Nomenclature}

$C$ concentration, $\mathrm{mol} \mathrm{m}^{-3}$

$E_{\text {act }}$ activation encrgy, $\mathrm{J} \mathrm{mol}^{-1}$

$F$ molar flow rate, $\mathrm{mol} \mathrm{s}^{-1}$

$k_{1} \quad$ reaction rate constant, $\mathrm{mol} \mathrm{kg} \mathrm{kg}^{-1} \mathrm{~s}^{-1} \mathrm{~Pa}^{-1}$

$k_{1, \infty}$ pre-exponential factor, $m o \mathrm{~kg}^{-1} \mathrm{~s}^{-1} \mathrm{~Pa}^{-1}$

$k_{2}$ rate constant of oxygèn adsorption, $m \mathrm{~mol} \mathrm{~kg}^{-1}$ $\mathrm{s}^{-1} \mathrm{~Pa}^{-1}$

$k_{\mathrm{r}} \quad$ reaction rate constant, $\operatorname{mol~kg}{ }^{-1} \mathrm{~s}^{-1} \mathrm{~Pa}^{n+m}$

$k_{1} \quad=k_{1} / k_{2} P_{\mathrm{O}_{2}}, \mathrm{~Pa}^{-1}$

$k_{\mathrm{r}, \infty}$ pre-exponential factor, $\mathrm{mol} \mathrm{kg} \mathrm{kg}^{-1} \mathrm{~s}^{-1} \mathrm{~Pa}^{n+m}$

$K \quad$ adsorption constant, $\mathrm{Pa}^{-1}$

$M_{\text {cat }}$ catalyst mass, $\mathrm{kg}$

$N \quad$ rotation speed of the impeller, $\mathrm{s}^{-1}$

$P \quad$ (partial) pressure, $\mathrm{Pa}$

$R \quad$ gas constant, $\mathrm{J} \mathrm{mol}^{-1} \mathrm{~K}^{-1}$

$R_{\mathrm{HC}}$ reaction rate, mol $\mathrm{HC}$ converted $\mathrm{kg}_{\mathrm{cat}}{ }^{-1} \mathrm{~s}^{-1}$

$R_{\exp }$ experimentally determined reaction rate, $\operatorname{mol~HC}$ converted $\mathrm{kg}_{\text {cat }}{ }^{-1} \mathrm{~s}^{-1}$

$T$ temperature, $\mathrm{K}$

$u_{\mathrm{g}} \quad$ superficial gas velocity, $\mathrm{m} \mathrm{s}^{-1}$

$x$ mole fraction, -

$z$ axial position, $\mathrm{m}$

$\varepsilon \quad$ bed porosity, -

$\rho_{\mathrm{s}} \quad$ density of the catalyst, $\mathrm{kg} \mathrm{m}^{-3}$

$v \quad$ stoichiometric coefficient, -

\section{Subscripts and superscripts}

f feed

$\mathrm{HC}$ hydrocarbon

$j$ component $j$

$m$ reaction order with respect to water, see model IV

$n$ reaction order with respect to hydrocarbon, see model IV

out outlet

\section{References}

[1] R. Prasad, L. A. Kennedy and E. Ruckenstein, Catalytic combustion, Catal, Rev-Sci. Eng. 26 (1984) 1-58.

[2] M. F. M. Zwinkels, S. G. Jaras and P. G. Menon, Catalytic materials for high-temperature combustion, Culal. Rev-Sci. Eng., 35 (1993) 319-358.

[3] B. A. Tichenor and M. A. Palazzolo, Destruction of volatile organic compounds via catalytic incineration, Environ. Prog., 6 (1987) $172-176$.

[4] I. Mazzarino and A. A. Barresi, Catalytic combustion of VOC mixtures in a monolithic reactor, Catal. Todaj', 17 (1993) 335348.

[5] J. Hermia and S. Vigneron, Catalytic incineration for odour abatement and VOC destruction, Catal. Today, 17 (1993) 349358.

[6] L. van de Beld, R. A. Borman, O.R. Derkx, B. A. A. van Woezik and $K$. R. Westerterp, Removal of volatile organic compounds from polluted air in a reverse flow reactor: an experimental study, Ind. Eng. Chem. Res., 33 (1294) 2946-2956.

[7] L. van de Beld, M. P. G. Bijl, A. Reinders, B. van der Werr and K. R. Westerterp, The Catalytic oxidation of organic contaminants in a packed bed renctor, Chem. Eng. Sci., 49 (1994) $4361-4373$.

[8] J. J. Spivey, Complete catalytic oxidation of volatile organics. Ind. Eng. Chem., Prod. Res. Deu., 26 (1987) 2165-2180.

[9] A. A. Barresi and G. Baldi, Deep catalytic oxidation kinetics of benzene/ethenyl benzene mixtures, Chem. Eng. Sci., 47 (1992) $1943-1953$.

[10] G. I. Golodets, Heterogeneous catalytic reactions involving molecular oxygen, Studies in Suface Science and Catalysis, Elsevier, Amsterdam, 1983, Vol. 15.

[11] Dow Chemical Company, Smusolv, Modeling and Simulation Software, Version 3.0, 1993, Midland, MI, USA.

[12] S. Wedel and J. Villadsen, Falsification of kinetic parameters by incorrect treatment of recirculation data, Chem. Eng. Sci, 38 (1983) $1346-1349$

[13] P. C. Borman, The selective oxidation of ethene in a wall-cooled tubular packed bed reactor, Thesis, University of Twente, The Netherlands, 1993.

[14] D. L. Trimm and C. W. Lam, The combustion of methane on platinum-alumina fibre catalysts. I, Chem. Eng. Sci., 35 (1980) $1405-1413$.

[15] C. F. Cullis, T. G. Nevell and D. L. Trimm, Role of the catalyst support in the oxidation of methane over palladiun, J. Chem. Soc., Faraday Trans. I, 68 (1972) 1406-1412.

[16] C. Kemball and W. R. Patterson, The catalytic oxidation of ethylene on palladium films, Proc. R. Soc. London, Ser. A. 270 (1962) 219-231.

[17] F. H. Ribeiro, M. Chow and R. A. Dalla Betta, Kinetics of the complete oxidation of methane over supported palladium catalysts, J. Catal., 146 (1994) 537-544.

[18] B. Simon and D. Vortmeyer, Measured and calculated migrating speeds of reaction zones in a fixed bed reactor, a quantitative comparison, Chem. Eng. Sci., 33 (1978) 109-114.

[19] J. R. Hawkins and S. E. Wanke, The oxidation of ethylene over a supported platinum catalyst, Con. J. Chem. Eng., 57 (1979) $621-626$. 